\title{
Differences in aerobic capacity among students with regard to their level of nutritional status ${ }^{1}$
}

\author{
Mateja Kunješić ${ }^{2}$ \\ Marko Badrić ${ }^{3}$ \\ Ivan Prskalo ${ }^{4}$
}

\begin{abstract}
Due to contemporary lifestyle, nutritional status of students is poorer and therefore it negatively affects the aerobic capacity. The purpose of this study was to determine the differences in aerobic capacity among female students of Faculty of Teacher Education with regard to their level of nutritional status. The study included 281 female students of the Faculty of Teacher Education, University of Zagreb. The sample of variables consisted of anthropometric measures: body height, body weight, sub-scapular and triceps skinfolds. Aerobic capacity was measured by 20 meter shuttle run test and nutritional status was determined by the body mass index (BMI). The subjects were divided into four groups according to their nutritional status: underweight, normal body weight, overweight and obese. Mean values of the BMI place the students into normal weight group, however, mean values of aerobic capacity show that students achieved poor results. Kruskal Wallis test and its post-hoc test (multiple comparisons for all groups with Bonferroni adjustment) for determining the difference between subsamples according to the level of nutritional status among students show that the subsamples differ in four of the five variables that describe the morphological characteristics (body weight, BMI, sub-scapular skinfold, triceps skinfold) as well as in aerobic capacity. The results obtained in this study show that the increased body mass have extremely high impact on the aerobic capacity results. It can be concluded that the tested students' aerobic capacity is poor and students with normal body weight have better aerobic capacity than overweight or obese students.
\end{abstract}

Keywords: body mass index; faculty students; functional capacity; 20 m shuttle run test; VO2 max

\section{Introduction}

Aerobic capacity (VO2 max) is the "maximal amount of oxygen that human body can utilize per minute of activity or physical workout" (Dhara \& Chatterjee, 2015, p. 9). It is the most frequently used measure of cardiorespiratory fitness (Grant, Corbett, Amjad, Wilson, \& Aitchison,

\footnotetext{
1 Paper has been presented on "International Lifelong Learning and Leadership for all" conference.

2 Ph.D., University of Zagreb, Faculty of Teacher Education, Department for kinesiology education, mateja.kunjesic@ufzg.hr

3 Ph.D., University of Zagreb, Faculty of Teacher Education, Department for kinesiology education, marko.badric@ufzg.hr

4 Ph.D., University of Zagreb, Faculty of Teacher Education, Department for kinesiology education, ivan.prskalo@,ufzg.hr
} 
Kunješić, M., Badrić, M., \& Prskalo, I. (2016). Differences in aerobic capacity among students with regard to their level of nutritional status. International Journal of Human Sciences, 13(1), 414-420. doi:10.14687/ijhs.v13i1.3563

1995), which shows cardiorespiratory durability of an individual (Dhara \& Chatterjee, 2015). Furthermore, VO2 max is affected by many factors, such as physical training, genetics, age, gender and body composition (Hoeger, W.W.K \& Hoeger S.A., 2014).

The VO2 max can be measured using submaximal and maximal tests, by methods which can be direct or indirect (Nabi, Rafiq, \& Qayoom, 2015). Considering that the direct measurement of VO2 max is expensive, multistage progressive shuttle run test (MST) is the most commonly used measure. MST can at the same time include a large number of participants, but it is a maximal test which has potential health risk and participants have to be highly motivated to invest truly maximal effort (Grant et al., 1995).

Research studies have established that VO2 max is a crucial physiological factor and has an important role in the determination of fitness and capacity of physical work under aerobic conditions (Ribisl \& Kachadorian, 1969). For women aged 13-19 years VO2 max under 25 $\mathrm{ml} / \mathrm{kg} / \mathrm{min}$, and for women aged $20-29$ years under $23.6 \mathrm{ml} / \mathrm{kg} / \mathrm{min}$ have been taken as the normative for very poor fitness (The Physical Fitness Specialist Certification Manual, 1998).

International standard of physical activity is maximal oxygen uptake expressed as millilitre $/ \mathrm{kg} /$ minutes because the absolute value is highly affected by body weight (Shete, Bute, \& Deshmukh, 2014). It has been established that low level of physical activity affects body composition and the correlation between body composition and cardiovascular fitness is inversely proportional (Brooks, 2002).

Many cross-sectional studies prove that a low level of aerobic capacity is a feature of overweight adolescents and youth (Lee \& Arslanian, 2007; Ward et al., 1997). Ferreira (2013) as well as Pate, Wang, Dowda, Farrell, and O’Neill (2006) have proven that overweight and obese adolescents have lower cardiorespiratory fitness level than normal weight adolescents. Low level of cardiorespiratory fitness and adiposity in adolescence are both correlated with higher risk of mortality in adulthood (Apor, 2011), and it is well known that cardiorespiratory fitness is an independent determinant of a healthy lifestyle (Ferreira, Twisk, van Mechelen, Kemper, \& Stehouwer, 2005). Thus, the aim of this study was to determine differences in aerobic capacity among the Faculty of Teacher Education students with regard to their level of nutritional status.

\section{Methods}

The study included 281 first and second year students of the Faculty of Teacher Education, University of Zagreb. The measurement was conducted in the academic year 2014/15. All the participants were healthy and willing to participate in research. The sample of variables consisted of anthropometric measures: body height, body weight, sub-scapular and triceps skinfolds. All anthropometric measurements were performed according to the International Biological ProgramIBP instructions (Weiner \& Lourie, 1969). Body height was measured by using anthropometry and body weight with the help of digital scales. Skinfolds were measured by Lange skinfold calliper. Aerobic capacity was measured by multi-stage 20 meters - shuttle run test (Leger \& Lambert, 1982). Body mass index was calculated on the basis of the formula BMI $(\mathrm{kg} / \mathrm{m} 2=$ weight $(\mathrm{kg}) /($ height $(\mathrm{m}))^{2}$ (Garow \& Webster, 1985). Based on the calculated body mass index and the International Classification (WHO, 1997), the subjects were divided into four groups according to their nutritional status: underweight (below 18.50), normal body weight (18.50-24.99), overweight (25.0029.99) and obese (above 30.00).

\section{Statistical analysis}

Data analysis was performed with the program STATISTICA (data analysis software system), version 7.1. For all variables, basic descriptive parameters: arithmetic mean (M), standard 
deviation (SD), minimum (MIN) and maximum (MAX), Skewness and Kurtosis were calculated. The normality of the distribution of variables was tested by Kolmogorov-Smirnov test and the homogeneity of variance by Levene's Test. Since the results of these two tests were statistically significant, for establishing differences according to the level of nutrition status, nonparametric Kruskal Wallis test and its post-hoc test (multiple comparisons for all groups with Bonferroni adjustment) were used. Statistical significance was tested at a significance level of $p<0.05$.

\section{Results}

Table 1

Descriptive parameters for students' anthropometric measures and maximal oxygen

\begin{tabular}{lccccccc}
\hline & \multicolumn{7}{c}{$\mathrm{N}=281$} \\
\cline { 2 - 8 } & Mean & SD & Min & Max & Skew & Kurt & $\begin{array}{c}\mathrm{K}-\mathrm{S} \\
\text { test }\end{array}$ \\
\hline Height-cm & 167.31 & 6.74 & 150.00 & 189.00 & 0.32 & 0.00 & $\mathrm{p}<.10$ \\
Weight-kg & 61.53 & 11.45 & 41.00 & 135.50 & 2.32 & 10.01 & $\mathrm{p}<.01$ \\
BMI & 22.15 & 3.64 & 16.63 & 50.81 & 2.95 & 15.84 & $\mathrm{p}<.01$ \\
Sub-scapular skinfold & 15.72 & 6.61 & 5.80 & 46.00 & 1.25 & 2.21 & $\mathrm{p}<.01$ \\
Triceps skinfold & 21.06 & 6.41 & 8.40 & 50.00 & 0.97 & 2.16 & $\mathrm{p}<.10$ \\
V02 max & 28.80 & 6.08 & 18.50 & 50.80 & 0.72 & 0.21 & $\mathrm{p}<.01$ \\
\hline
\end{tabular}

Table 1 shows the basic descriptive parameters for the studied sample of participants. It can be seen in that students' average body height is $167.31 \mathrm{~cm}$ and body weight $61.53 \mathrm{~kg}$. BMI values are generally at comfortable levels of 22.15 , placing them in the group of normal weight adults according to the standards of the International Classifications (WHO, 1997). The values of skinfolds are in accordance with the norms (Mišigoj-Duraković, 2008). Results of maximum oxygen consumption (VO2 max) with the value of $28.80 \mathrm{ml} / \mathrm{kg} / \mathrm{min}$ show a poor level (The Physical Fitness Specialist Certification Manual, 1998).

Table 2

Results of the Kruskal $W$ allis test for determining the difference between subsamples defined by the degree of nutritional status $(p<0.05)$

\begin{tabular}{|c|c|c|c|c|c|c|}
\hline & \multirow{2}{*}{$\begin{array}{c}\text { Underweight } \\
4 \%\end{array}$} & \multirow{2}{*}{$\begin{array}{c}\begin{array}{c}\text { Normal } \\
\text { weight } \\
81 \%\end{array} \\
\text { Mean } \pm \text { SD }\end{array}$} & \multirow{2}{*}{$\begin{array}{c}\begin{array}{c}\text { Overweight } \\
10 \%\end{array} \\
\text { Mean } \pm \text { SD }\end{array}$} & \multirow{2}{*}{$\begin{array}{c}\text { Obese } \\
4 \% \\
\text { Mean } \pm \text { SD }\end{array}$} & \multicolumn{2}{|c|}{$\begin{array}{c}\text { Kruskal-Wallis } \\
\text { test }\end{array}$} \\
\hline & & & & & $\mathrm{H}$ & $\mathrm{P}$ \\
\hline Height-cm & $164.29 \pm 4.87$ & $167.47 \pm 6.82$ & $166.12 \pm 5.81$ & $170.29 \pm 8.06$ & 4.467 & 0.21 \\
\hline Weight-kg & $47.32 \pm 3.08$ & $59.03 \pm 6.35$ & $73.03 \pm 6.77$ & $98.80 \pm 17.82$ & 108.475 & 0.00 \\
\hline BMI & $17.61 \pm 0.54$ & $21.22 \pm 1.58$ & $26.67 \pm 1.14$ & $34.53 \pm 6.18$ & 127.827 & 0.00 \\
\hline Sub-scapular skinfold & $12.87 \pm 4.40$ & $14.60 \pm 5.60$ & $20.54 \pm 5.97$ & $29.35 \pm 8.76$ & 47.314 & 0.00 \\
\hline Triceps skinfold & $16.02 \pm 3.95$ & $20.07 \pm 5.43$ & $26.01 \pm 4.13$ & $34.07 \pm 10.14$ & 54.216 & 0.00 \\
\hline $\mathrm{V} 02 \max$ & $30.41 \pm 4.61$ & $29.41 \pm 6.12$ & $26.08 \pm 4.68$ & $21.51 \pm 2.32$ & 29.224 & 0.00 \\
\hline
\end{tabular}

M-mean result; $\mathrm{H}=\mathrm{h}$ - value; $\mathrm{p}=$ level of significance $(\mathrm{p}<0.05)$

Table 2 shows that $81 \%$ of the tested students had normal nutritional status, while $10 \%$ of students are in the group of overweight and $4 \%$ of students are in the group of obese students. On the other hand, $4 \%$ of students belong to an underweight group. The arithmetic means of 
Kunješić, M., Badrić, M., \& Prskalo, I. (2016). Differences in aerobic capacity among students with regard to their level of nutritional status. International Journal of Human Sciences, 13(1), 414-420. doi:10.14687/ijhs.v13i1.3563

subsamples according to the level of nutritional status are also given in Table 2. It is obvious that the students who belong to the group of obese are over 6 and $3 \mathrm{~cm}$ higher than underweight and normal weight students respectively. Another obvious difference is evident in body mass where the normal weight students have 40 kilograms less than obese students. Also, nominal differences in both skinfolds are also evident, with overweight and obese students having almost twice as bigger skinfold than underweight and normal weight students. Aerobic capacity results were lower in students with increased body mass, although it is evident that all four sub-samples have a very low level of aerobic capacity.

Kruskal Wallis test results for determining the difference between subsamples according to the level of nutritional status among $1^{\text {st }}$ and $2^{\text {nd }}$ year students of the Faculty of Teacher Education show that the subsamples differ in four of the five variables that describe students' morphological characteristics. Significant differences between subsamples defined according to the level of nutritional status appear in the variables body weight, BMI, sub-scapular skinfold and triceps skinfold $(\mathrm{p}=0.00)$. Also, significant differences appear in the variables for estimating the maximum oxygen consumption $(\mathrm{p}=0.00)$.

Table 3

Post hoc for the variable "body weight" according to the level of nutritional status

\begin{tabular}{ccccc}
\hline Body weight & Underweight & Normal weight & Overweight & Obese \\
\hline Underweight & & & \\
\hline Normal weight & $\mathbf{0 . 0 0}$ & & \\
\hline Overweight & $\mathbf{0 . 0 0}$ & $\mathbf{0 . 0 0}$ & \\
\hline Obese & $\mathbf{0 . 0 0}$ & $\mathbf{0 . 0 0}$ & 1.00 \\
\hline
\end{tabular}

Table 4

Post hoc for the variable "BMI" according to the level of nutritional status

\begin{tabular}{ccccc}
\hline BMI & Underweight & Normal weight & Overweight & Obese \\
\hline Underweight & & & & \\
\hline Normal weight & $\mathbf{0 . 0 0}$ & & & \\
\hline Overweight & $\mathbf{0 . 0 0}$ & $\mathbf{0 . 0 0}$ & & \\
\hline Obese & $\mathbf{0 . 0 0}$ & $\mathbf{0 . 0 0}$ & 1.00 \\
\hline
\end{tabular}

Table 5

Post hoc for the variable "sub-scapular skinfold" according to the level of nutritional status

\begin{tabular}{ccccc}
\hline $\begin{array}{c}\text { Sub-scapular } \\
\text { skinfold }\end{array}$ & Underweight & Normal weight & Overweight & Obese \\
\hline Underweight & & & & \\
\hline Normal weight & 1.00 & & \\
\hline Overweight & $\mathbf{0 . 0 0}$ & $\mathbf{0 . 0 0}$ & \\
\hline Obese & $\mathbf{0 . 0 0}$ & $\mathbf{0 . 0 0}$ & 0.40 \\
\hline
\end{tabular}


Kunješić, M., Badrić, M., \& Prskalo, I. (2016). Differences in aerobic capacity among students with regard to their level of nutritional status. International Journal of Human Sciences, 13(1), 414-420. doi:10.14687/ijhs.v13i1.3563

Table 6

Post hoc for the variable "triceps skinfold" according to the level of nutritional status

\begin{tabular}{ccccc}
\hline $\begin{array}{c}\text { Triceps } \\
\text { skinfold }\end{array}$ & Underweight & Normal weight & Overweight & Obese \\
\hline Underweight & & & & \\
\hline Normal weight & 0.09 & & \\
\hline Overweight & $\mathbf{0 . 0 0}$ & $\mathbf{0 . 0 0}$ & \\
\hline Obese & $\mathbf{0 . 0 0}$ & $\mathbf{0 . 0 0}$ & 1.00 \\
\hline
\end{tabular}

Table 7

Post hoc for the variable "VO2 max" according to the level of nutritional status

\begin{tabular}{ccccc}
\hline V02 max & Underweight & Normal weight & Overweight & Obese \\
\hline Underweight & & & & \\
\hline Normal weight & 1.00 & & & \\
\hline Overweight & 0.09 & $\mathbf{0 . 0 2}$ & \\
\hline Obese & $\mathbf{0 . 0 0}$ & $\mathbf{0 . 0 0}$ & 0.10 \\
\hline
\end{tabular}

Results of post-hoc test (multiple comparisons for all groups (Siegel \& Castellan, 1988)) for determining the difference between the groups according to the level of nutritional status) are shown in Tables 3-7. It was determined that for the variable body weight students of normal weight and those who are underweight $(\mathrm{p}=0.00)$ have lower body weight than students who are overweight or obese. Identical differences appear with variable BMI. With variables for estimating both skinfolds, the differences are not observed between underweight and normal weight students, or between obese and overweight students. The differences are, however, apparent between students of normal weight $(\mathrm{p}=0.00)$ and obese and those who are overweight. For the variable VO2 $\max$ it can be seen that students of normal weight had significantly better results $(\mathrm{p}=0.00)$ than students who are obese or overweight. Likewise, no significant differences were observed between obese and overweight students $(\mathrm{p}=0.10)$.

\section{Discussion}

The aim of this study was to determine the differences in aerobic capacity among students with regard to their level of nutritional status, which was determined by BMI according to WHO classification (1998). Mean value of BMI (22.15) places students into the group of normal weight. Similar results were obtained with participants from Saudi Arabia whose mean BMI value was 22.9 (El-Qudah, Al-Omran, Abu-Alsoud, \& Al-Shek Yousef, 2012), but 17.6\% of students from Saudi Arabia were underweight, $20.3 \%$ were overweight and $6.7 \%$ obese. In this research $10 \%$ of students from Zagreb belong to the group of overweight and $4 \%$ to the group of obese and underweight. Abdull, Muniandy, and Ajan (2012) showed in their research that 10\% of students from Malaysia were overweight and 17.8\% were underweight. In the research by Farreda, Hussein, and Helmy (2012), 29.5\% participants from Kuwait were overweight and 12.8\% were obese. It can be concluded that students from Zagreb have much better nutritional status than students from the reported studies.

Mean value of VO2 max of students in this research was $28.8 \mathrm{ml} / \mathrm{kg} / \mathrm{min}$ which is a poor result. Better results in aerobic capacity $(37.85 \mathrm{ml} / \mathrm{kg} / \mathrm{min})$ were achieved by students from India 
Kunješić, M., Badrić, M., \& Prskalo, I. (2016). Differences in aerobic capacity among students with regard to their level of nutritional status. International Journal of Human Sciences, 13(1), 414-420. doi:10.14687/ijhs.v13i1.3563

(Nabi et al, 2015) as well as students from Libya (44.8 ml $/ \mathrm{kg} / \mathrm{min})$ and Malaysia $(45.5 \mathrm{ml} / \mathrm{kg} / \mathrm{min}$ ) (Razak, Maizi, \& Muhamad, 2013). Students in the research by Pribis, Burtnack, McKenzie, and Thayer (2010) had higher BMI (24), body weight (65.6 kg) and better VO2 max $(43.2 \mathrm{ml} / \mathrm{kg} / \mathrm{min})$ than students from Zagreb.

Even though students' aerobic capacity is poor, significant differences between groups according to nutritional status were obtained. That is, students who are underweight and normal weight have better aerobic capacity than overweight and obese students. Similar results were obtained in other studies, i.e. non-obese students had higher VO2 max values than the obese (Nabi et al, 2015; Chouhan, Trigotra, Dashora, \& Mangat, 2014).

Although there was significant difference in VO2 max according to nutritional status, Moraes Ferrari, Bracco, Matsudo, \& Fisberg (2013) have proven in their longitudinal study that a decline in VO2 max is greater in normal weight individuals than in those who are overweight.

Limitations of this research are reflected in the sample, which represents only one faculty and therefore the results of this study cannot be generalized to the entire population. In some future field research with students of this age it is necessary to sample participants from several faculties. Also, the obtained conclusions of this study may be useful in future studies of aerobic capacity in young people.

\section{Conclusion}

The results obtained in this study show that the increased body mass has extremely high impact on the aerobic capacity results. Students who have an increased body mass index have a lower aerobic capacity. Daily physical exercise, especially the exercise in the aerobic mode, may contribute to progress in the development of aerobic capacity of young people.

\section{References}

Abdull, H.N.H., Muniandy, N.D., \& Ajan, D. (2012). Nutritional Status and Eating Practices among University Students in Selected Universities in Selangor, Malaysia. Asian Journal of Clinical Nutrition, 4 (3): 77-87

Apor, P. (2011). Measure of fitness and physical activity related to cardiovascular diseases and death. OrvHetil, 152: 107-113.

Brooks, L.L. (2002). The effect of after school physical activity and adult encouragement on

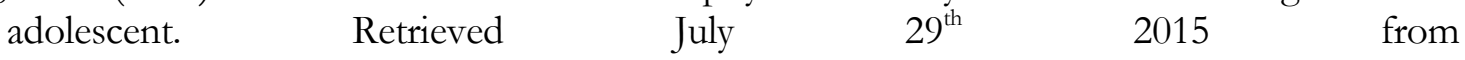
http://www2.uwstout.edu/content/lib/thesis/2002/2002brooksl.pdf

Chouhan, S., Trigotra, S., Dashora, L.S., \& Mangat, E.K. (2014). An Assessment of CardioRespiratory Fitness in Normal Weight, Overweight and Obese Young Adults. IJBAP, 3 (1): 24-29.

Dhara, S., \& Chatterjee, K. (2015). A Study of VO2 max in Relation with Body Mass Index (BMI) of Physical Education Students. Res. J. Physical Education Sci, 3 (6): 9-12.

El-Qudah, J.M., Al-Omran, H., Abu-Alsoud, B., Al-Shek Yousef, T.O.I. (2012). Nutritional Status among a Sample of Saudi College Students. Current Research Journal of Biological Sciences, 4(5): 557-562.

Farreda, H.M., Hussein, E.A., Helmy, H.M. (2012). Assessment of Nutritional Status of Some females University Students in State of Kuwait. Retrieved August $15^{\text {th }} 2015$ from http://cje2.ufzg.hr/ojs/CJE_Vol.17_No.2_2015_guidelines.pdf 
Kunješić, M., Badrić, M., \& Prskalo, I. (2016). Differences in aerobic capacity among students with regard to their level of nutritional status. International Journal of Human Sciences, 13(1), 414-420. doi:10.14687/ijhs.v13i1.3563

Ferreira, F.S. (2013). Relationship between Physical Fitness and Nutritional Status in a Portuguese Sample of School Adolescents. J Obes Weight Loss Ther, 3,190. doi: 10.4172/21657904.1000190

Ferreira, I., Twisk, J.W., van Mechelen, W., Kemper, H.C., \& Stehouwer, C.D. (2005). Development of fatness, fitness, and lifestyle from adolescence to the age of 36 years: determinants of the metabolic syndrome in young adults: the Amsterdam growth and health longitudinal study. Arch Intern Med, 165, 42-48.

Garow, J.S., \& Webster, J.D. (1985). Quetelet's index (W/H2) as a measure of fatness. Int J Obes Relat Metab Disord, 9, 147-53.

Grant, S., Corbett, K., Amjad, A.M., Wilson, J., \& Aitchison, T. (1995). A comparison of methods of predicting maximum oxygen uptake. BrJ Sports Med, 29, 147-152.

Lee, S.J., \& Arslanian, S.A. (2007). Cardiorespiratory fitness and abdominal adiposity in youth. EurJ ClinNutr, 61, 561-565.

Leger, L.A., \& Lambert, J. (1982). A maximal multistage 20-m shuttle run test to predict VO2max. European Journal of Applied Physiology, 49, 1-12.

Hoeger, W.W.K., \& Hoeger, S.A. (2014). Principles and Labs for Fitness and Wellness (13 Ed.). Boston: Cengage Learning

Mišigoj-Duraković, M. (2008). Kinantropologija. Zagreb: Faculty of Kinesiology University of Zagreb.

Moraes Ferrari, G.L., Bracco, M.M., Matsudo, V.K., \& Fisberg, M. (2013). Cardiorespiratory fitness and nutritional status of schoolchildren: 30-year evolution. J Pediatr (Rio J), 89 (4), 366-73. doi: 10.1016/j.jped.2012.12.006.

Nabi, T., Rafiq, N., \& Qayoom, O. (2015). Assessment of cardiovascular fitness [VO2 max] among medical students by Queens College step test. International Journal of Biomedical and Advance Research, 6 (05), 418-421.

Pate, R.R., Wang, C.Y., Dowda, M., Farrell, S.W., \& O’Neill, J.R. (2006). Cardiorespiratory fitness levels among US youth 12 to 19 years of age: findings from the 1999-2002 National Health and Nutrition Examination Survey. Arch PediatrAdolesc Med, 160, 1005-1012

Pribis, P., Burtnack, C.A., McKenzie, S.O., \& Thayer, J. (2010). Trends in Body Fat, Body Mass Index and Physical Fitness Among Male and Female College Students. Nutrients, 2, 10751085; doi:10.3390/nu2101075

Razak, M.R.A., Maizi, I.E., \& Muhamad, T.A. (2013). Physical Activity, Aerobic Fitness and Body Composition among Students in Malaysia and Libya. Asian Social Science, 9 (16), 168-175.

Ribisl, P.H., \& Kachadorian, W.A. (1969). Maximal oxygen intake prediction in young men and middle aged males. J. Sports Med. \& Phys Fitness, 9, 17.

Shete, A.N., Bute, S.S., \& Deshmukh, P.R. (2014). A Study of $\mathrm{VO}_{2}$ Max and Body Fat Percentage in Female Athletes. Journal of Clinical and Diagnostic Research, 8 (12), BC01-BC03.

Siegel, S., \& Castellan, Jr., N.J. (1988). Nonparametric statistics for the behavioural sciences, (2 ${ }^{\text {nd }}$ ed.). New York: McGraw-Hill

The Physical Fitness Specialist Certification Manual 1998. Retrieved July $29^{\text {th }} 2015$ from http://www.machars.net/v02max.htm

Ward, D.S., Trost, S.G., Felton, G., Saunders, R., Parsons, M.A., Dowda, M., \& Pate, R.R. (1997). Physical activity and physical fitness in African-American girls with and without obesity. Obes Res, 5(6), 572-7.

Weiner, J.S., \& Lourie, J.A. (1969). Human Biology: A Guide to Field Methods. London. Internat. BioI. Programme

WHO (1997). Obesity: Preventing and Managing the Global Epidemic. Retrieved September $2^{\text {nd }}$ 2015 from file:///C:/Users/User\%201/Downloads/WHO NUT NCD 98.1 (p1158).pdf 